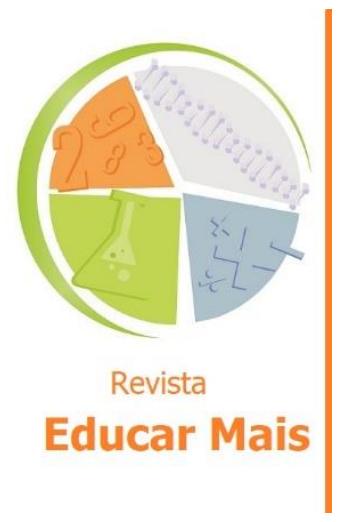

\section{Contando história: memória de velhos e o resgate oral da educação de imigrantes pomeranos}

\section{Telling story: memory of old and the oral rescue of the education of immigrant pomeran}

\author{
Graciéli Abrahm Griep Timm¹; Márcia Helena Sauaia Guimarães Rostas ${ }^{1}$
}

\title{
RESUMO
}

O presente artigo tem por objetivo registrar através da oralidade fragmentos da história da educação do campo, dos imigrantes pomeranos, nos municípios de Canguçu e São Lourenço do Sul, no estado do Rio Grande do Sul, através das memórias de um casal de idosos, Vô Werno e Vó Eddy, filhos de imigrantes alemães. Utilizamos a tradição oral, Bosi (1994) e Vansina (2010), para o registro histórico das narrativas. Os comentários foram balizados, prioritariamente, por Freire (1987).

Palavras-chave: Educação do campo; Tradição oral; Pomeranos.

\begin{abstract}
This article aims to record and, thus, rescue fragments of the history of rural education of Pomeranian immigrants in the municipalities of Canguçu and São Lourenço do Sul, in the state of Rio Grande do Sul, through the memories of a couple of elderly, Grandpa Werno and Grandma Eddy, children of German immigrants. We used the oral tradition, Bosi (1994) and Vansina (2010), for the historical record of the narratives. The comments were analysed on Freire (1987).
\end{abstract}

Keywords: Education in the field; Oral tradition; Pomeranians.

\section{INTRODUÇÃO}

Registrar e, a partir deste ato, coletar narrativas sobre educação, utilizando a metodologia da tradição oral, é, também, uma forma de conhecer como se constituíram os saberes e os fazeres tradicionais de uma comunidade. As histórias contadas, através de gerações, nos municípios de Canguçu e São Lourenço do Sul, no estado do Rio Grande do Sul, no século passado, traduzem um pedaço da vida daquele povo a partir de fragmentos da trajetória acerca da educação do campo que por vezes se encontra perdida entre os depoimentos e a memória dos que viveram naquele espaço-temporal, e que podem se perder ao longo dos anos.

Os relatos destas pessoas mais velhas, que viveram esta época, são narrativas orais que enunciam o início da colonização repletas de desejos aforados pela nova perspectiva de vida, sem deixar de lado a cultura e os costumes trazidos da Pomerânia.

\footnotetext{
${ }^{1}$ IFSul - Instituto Federal de Educação, Ciência e Tecnologia do Sul-rio-grandense, Pelotas/RS - Brasil.
} 
Beilke (2016, p. 32) descreve o povo pomerano como "[...] oriundo da Pomerânia [...] um território da região nordeste do Reino da Prússia (atual Alemanha); porém a maior parte dessas terras foi perdida pelos autóctones pomeranos alemães ao fim da Segunda Guerra Mundial e hoje pertence à Polônia".

É bem interessante conhecer este povo que saiu de sua terra em busca de novas oportunidades. Hackenhaar (2018, p. 52) destaca que esses imigrantes

[...] vislumbravam construir além-mar uma "nação livre" para onde pudessem transportar todos os elementos de sua rica cultura. No Brasil [...] estabeleceram-se principalmente em três estados, sendo eles o Rio Grande do Sul, Santa Catarina e Espirito Santo, onde construíram comunidades baseadas principalmente na agricultura familiar e na policultura. [...] foram enviados para terras de difícil acesso, e por serem geralmente isoladas de outros núcleos de povoamento, acabou sendo o isolamento geográfico um fator de fortalecimento étnico destes grupos.

A autora discorre ainda que:

[...] Entre as colônias alemãs fundadas no Rio Grande do Sul, a Colônia de São Lourenço, fundada no ano de 1858 por Jacob Rheingantz, foi a que mais recebeu imigrantes pomeranos. Rheingantz beneficiou-se com a Lei de Terras de 1854 para adquirir 52 mil hectares de terra devoluta, a qual ele pretendia colonizar com 1440 famílias dentro do período de cinco anos. (p. 52)

Sendo assim percebe-se que desde o princípio do processo de colonização os imigrantes pomeranos passaram por muitas dificuldades em uma terra desconhecida, mas mesmo assim sempre esteve presente a preocupação com a educação de seus filhos.

E é neste município, São Lourenço-RS os registros da constituição das primeiras escolas. São escolas organizadas por famílias de colonos, que percebiam, como bem enfatizado pelos informantes, a necessidade de educarem seus filhos no ambiente formal. Esta não era uma tarefa fácil e para que isso fosse possível foi necessário a organização em pequenos grupos, denominados de comunidades. Sua disposição, nos primeiros tempos de colonização estava sob incumbência

[d]os imigrantes [que] preocuparam-se em ter escolas nas suas comunidades e mesmo com dificuldades as mantinham, como também eram responsáveis pela remuneração dos professores, pois a instrução pública não existia no meio rural daqueles colonos. Tem-se a constatação de que em 1877 eram dezesseis escolas particulares mantidas pelos moradores na colônia de São Lourenço. Depois de vinte anos de fundação da colônia, a pedido de um senhor chamado Jacob Rheingantz, instalou-se a primeira escola pública, ainda desprovida de professor. A instalação de escolas deu-se paralelo a constituição das igrejas, pois não se poderia imaginar uma comunidade sem templo. (TIMM, 2009, p.22).

Os personagens, informantes de nossos registros, viveram um tempo de muitas repressões em se tratando de educação, pois nas escolas os professores sem formação pedagógica regiam uma doutrina baseada na religião pois os mesmos eram pastores das comunidades e exerciam com muito rigor e força sua autoridade, a educação costumava ser - de modo extremo-inflexível, permeada por castigos físicos. Os relatos de suas memórias, vivências daquele tempo, traça o impacto das mudanças ocorridas na comunidade e na educação. Nosso convite é para que o nosso leitor entre no universo desta narrativa e aprecie as lembranças deste tempo. 


\section{A TRADIÇÃO ORAL COMO METODOLOGIA DE PESQUISA}

Uma preocupação, recorrente nas pesquisas que envolvem a educação do/no campo, é a fonte. Esta preocupação vem diante da riqueza de informações e experiências que temos naquele ambiente e a ausência de registros formais. Encontramos alguns anais, porém, não na quantidade com que encontramos subjugado nas vivências de um povo. Desta forma nossa contribuição vem, também, no sentido de utilizar um instrumento fidedigno como as narrativas através da metodologia da tradição oral. De acordo com Vansina (2010):

[...] uma sociedade oral reconhece a fala não apenas como um meio de comunicação diária, mas, também, como um meio de preservação da sabedoria dos ancestrais, venerada no que poderíamos chamar elocuções-chaves, isto é, a tradição oral. A tradição pode ser definida, de fato, como um testemunho transmitido verbalmente de uma geração para outra. (p.139-140)

Partindo deste viés as informações coletadas são registradas e, portanto, preservadas na sabedoria ancestral. Freitas (2006) aponta a tradição oral como um dos gêneros em que a História Oral se divide, reforçando que esta não está presente, apenas, nas comunidades tidas como "iletradas" ou tribais, mas em sociedades rurais e urbanas pela metodologia de História Oral, onde as pessoas mantêm a cultura de repassar seus conhecimentos através do relato as futuras gerações.

Reforça, ainda, que em uma sociedade oral, por tradição:

[...] tudo que [se] considera importante para o perfeito funcionamento de suas instituições, para uma correta compreensão dos vários status sociais e seus respectivos papéis, para os direitos e obrigações de cada um, tudo é cuidadosamente transmitido [...] enquanto que [...] numa sociedade que adota a escrita, somente as memórias menos importantes são deixadas à tradição. (FREITAS, 2006, p. 20)

Diferentemente das fontes escritas, suas principais especialidades envolvem o verbalismo e os testemunhos contados através das gerações. Para M’Bow (2010, p. 24):

[...] a tradição oral que, até recentemente desconhecida, aparece hoje como uma preciosa fonte para a reconstituição da história [...] permitindo seguir o percurso de seus diferentes povos no tempo e no espaço, compreender, a partir de seu interior, a visão [...] do mundo, e apreender os traços originais dos valores que fundam as culturas e as instituições [...]

Vansina (2010), enveredando para a descrição metodológica, destaca que em história oral é necessário, ao historiador, um bom conhecimento da cultura, da sociedade e da língua ou línguas envolvidas naquele processo inventariado. Além disso ressalta a importância de "[...] adotar uma atitude sistemática diante das fontes, das quais devem ser recolhidas todas as variantes. "Diante disso a autora adverte que o historiador deve ter "[...] longa permanência em campo, que será tanto mais demorada quanto menor for a familiaridade [...] com a cultura em questão". (p.162)

Uma reflexão bastante importante, dentro deste viés metodológico, trazido pela autora é a de que o historiador, mesmo sendo um nativo do ambiente, não é um conhecedor profundo do espaço pesquisado. Vansina (2010) lembra que o conhecimento instintivo de alguém que estuda a história de seu povo não é suficiente para registro da tradição oral. É necessária a reflexão sociológica, com o rigor metodológico, redescobrindo a cultura, mesmo antes conhecida. A coleta requer muito tempo, paciência e reflexão a partir de um plano racional de trabalho, que leve em consideração as características particulares de cada caso. É preciso delimitar uma área restrita, as regras que determinam as variantes e estabelecer, a partir delas, os princípios da amostragem a serem adotados. 
No caso de nossa pesquisa serão aproveitadas histórias contadas pelos mais velhos em se tratando das primeiras escolas para alunos pomeranos tal como a forma como se dava esta educação nos tempos mais antigos.

A oralidade é uma forma muito antiga de reconhecer fatos contados em uma sociedade que vive a partir das lembranças. As histórias contadas diariamente preservam, de forma por vezes romântica, um tempo onde as pessoas sentavam-se em rodas de chimarrão, costume muito preservado entre as famílias pomeranas e contavam aos mais novos, sua trajetória de vida até aquele momento.

Através de seus testemunhos é possível (re) conhecer as dificuldades enfrentadas ao chegar neste novo lugar. Uma terra desconhecida, nativa, mas que na mala do viajante pomerano, trazia as lembranças de seus antepassados, costumes, que agora serão cunhados em outro espaço, em uma nova terra. Toda a trajetória, guardada no registro da memória, se perde com o contador se dele não fizer apontamentos, para que as gerações que virão e as de agora conheçam a saga e (re) conheçam os traços culturais, sociais e de fala. São os mais velhos que podem fazer este relato, e neste caso serão registradas histórias contadas pelos avós maternos da autora em conversas ditas informais.

\section{LEMBRANÇAS Vô WERNO E DA Vó EDDY SOBRE A EDUCAÇÃO E O PROFESSOR ARNOLDO HEMP}

Contam os mais velhos, e segundo registros de Bosenbecker (2012, p. 42), em meados de 1877, com a chegada das primeiras famílias de pomeranos sob a regência do sr. Jacob Rheingantz, começam a ser instaladas as cinco primeiras escolas para imigrantes nas proximidades de São Lourenço do Sul. Estas escolas eram de iniciativa privada, subsidiadas pelos colonos, para que seus filhos tivessem acesso à educação formal, e desta forma, esperavam que o governo, cumprisse com o combinado e, construísse, naquela localidade, instituições públicas.

O Sr.Jacob, primeiro imigrante a chegar na localidade, aclamado diretor da província de São Lourenço, na época da vinda dos colonos para aquela região, evidenciou a vontade de que a comunidade recebesse uma escola pública para atender as necessidades de formação dos filhos daqueles trabalhadores. Fez inúmeros questionamentos, ao governo, acerca dos lotes de terra, da implantação de escolas, da construção de igrejas, tendo os seus pedidos ignorados. Para elucidar estas informações Bosenbecker (2011), nos traz o seguinte relato:

Rheingantz continuou suas explicações negando que os lotes não estivessem medidos e demarcados. Acrescentou que tinha fundado, por conta própria, cinco escolas particulares, e que a criação da cadeira pública fora aprovada em assembleia provincial "a instâncias minhas (de Rheingantz) pelos deputados Nascimento Barcellos e Vieira da Cunha". (p. 45)

Bosenbecker (2011) aponta que além da ampliação da extensão das colônias, outras táticas das empresas colonizadoras, organizadas por pessoas influentes do governo, eram usadas para aumentar os lucros e os valores dos lotes de terras. A execução de obras de infraestrutura, construção de estradas, pontes, igrejas e escolas, consistiu em forte estratégia. Porém, diante da demora do atendimento a esta demanda tão premente desta comunidade, para atender a seus filhos pequenos, os colonos se organizaram na construção, por conta própria, das escolas. Estes espaços funcionavam junto as igrejas luteranas e tinham por professores os pastores, pessoas que adquiriram 
conhecimentos das letras em função dos estudos bíblicos que desenvolviam para subsidiar as suas pregações. No que tange a educação destas famílias Küster (2018) adverte que em virtude dos

pomeranos serem um povo germânico e de o ensino ofertado a seus descendentes ser, à época, em língua alemã, por meio das escolas comunitárias, fez com que tal política impactasse esse grupo de maneira violenta. A análise do Ofício Reservado à Política de Nacionalização no 4, de 24 de janeiro de 1938, expedido pelo chefe de Estado-Maior do Exército ao ministro da Guerra, permite afirmar que "a tônica do documento é toda ela posta nos perigos que a presença de núcleos estrangeiros organizados, trazem à segurança nacional". Entre os núcleos de imigrantes que mais representavam perigo, estavam os italianos e alemães. Estes eram vistos como ameaça à nação brasileira, especialmente os alemães, considerados os mais organizados, em função do "isolamento em que procuram viver, transmitindo aos seus descendentes a língua, costumes, crença, mentalidade, cultura e patriotismo", demonstrando um "nível articulado de organização social, cultural e mesmo ideológica. (p. 17)

Podendo ser por isso que havia tão pouco interesse e por consequência descaso por parte das autoridades com a educação dos povos oriundos destas regiões (Itália e Alemanha), em virtude da força e organização destes povos, que por muito tempo conservaram costumes da cultura, principalmente na fala do dialeto pomerano.

O pastor Arnoldo Hemp assumiu como professor da comunidade religiosa de Taquaral, lugar em que a senhora Eddy Milech, minha avó materna, uma das personagens retratadas neste artigo, foi estudante. Apresentada as primeiras letras naquele local estudou da classe de alfabetização à $4^{a}$ série, em salas multisseriadas, por volta do ano de 1968.

Uma boa contadora de história, transmitiu pela oralidade, a seus netos, as dificuldades da época. O acesso à escola se dava à cavalo. Professor e alunos chegavam com seus animais, mas eram as crianças quem cuidavam dos bichos. Dava água, pasto e sombra preparando-os para o retorno. As primeiras turmas eram somente de meninos. Alguns anos depois as meninas também passaram a receber instrução e participar das aulas na escola. O pastor, segundo a Vó Eddy, era um professor exigente e rigoroso. Ele mantinha, dentro do espaço da igreja, meninos de um lado e meninas de outro, sem que houvesse qualquer forma de comunicação.

Os alunos não possuíam cadernos para seus apontamentos. Um pequeno quadro verde, conhecido à época como "Ardósia", era o espaço em que escreviam utilizando carvão vegetal, e liam, suas lições, repetidamente, até decorá-las, dando lugar a um novo conteúdo. A cada lição decorada o quadro era apagado para apresentação da seguinte. Os alunos precisavam ter muita atenção com relação aos conteúdos apresentadas, ao apagar o quadro, não lhes sobravam registros, desta forma não havia como retomar se surgisse alguma dúvida.

Contava a vó Eddy, que o professor atendia quatro a cinco turmas, diferenciadas, em níveis de aprendizagem distintos, em um mesmo ambiente. Os alunos de quarto ano que não alcançavam os objetivos propostos pelo professor e previstos para aquele ano letivo, repetiam a etapa.

Contava ela também, que o professor aplicava castigos rigorosos nas crianças que desobedecessem às normas impostas àquele espaço ou estivessem desatentos as aulas e/ou atividades. As famílias, por sua vez, acreditavam que o rigor era necessário para que houvesse qualidade na educação de 
seus filhos. Desta forma as atitudes não eram questionadas e os alunos eram colocados de joelhos sobre grãos, tampas e outros elementos e recebiam, ainda, agressões físicas.

O mesmo professor era o pastor responsável pelos sacramentos da igreja. Ministrava batismos, casamentos, confirmações e os alunos eram "obrigados", agora como fiéis, a decorar, através de questionários, textos bíblicos que seriam cobrados em um domingo de culto. O pastor, clérigo máximo da comunidade, arguia, também no domingo, as crianças, agora com o poder "divino" de punição. Se alguma criança esquecesse o catecismo e/ou cometesse algum equívoco, era motivo de balbúrdia entre as pessoas da comunidade. A família sentia-se ridicularizada por ter um filho que não conhecia a palavra de Deus com afinco e, portanto, cometia erros dentro da igreja, órgão máximo daquele local.

A tradição oral permite a vivência, através da memória. Na volta do fogão a lenha, rodeado dos cinco netos, nossos avós relembravam o passado e registravam, em nossas memórias, a história não contada, mas vivida, da nossa comunidade. Viveram além dos 80 anos de vida, com mais de 60 anos de casamento, e colecionaram, ao longo de décadas, muitas histórias e lembranças, dignas de registro.

Porém o que se percebe é um descaso com o passado da humanidade, principalmente dos povos que viveram no campo devido a sua cultura, a sua forma humilde de se expressar, os erros e acertos na comunicação, fazendo com que muitas vezes pessoas com histórias incríveis não as tenham contada devido à preocupação intensa a detalhes técnicos. Então a história oral vem como aporte de registro destas memórias incríveis dos nossos personagens passados. Sobre isto transcreve Ferreira e Amado (2006), quando dizem que:

O estudo da oralidade veio sendo ensaiado a partir da antropologia, no âmbito da pesquisa dos processos de transmissão das tradições orais, principalmente aquelas pertencentes a sociedades rurais, onde os modos de transmissão e conhecimento ainda transitam, de maneira relevante, pelos caminhos da oralidade. A tradição oral foi, então, um objeto de conhecimento constitutivo do corpus teórico da antropologia e também um meio de aproximação e interpretação das culturas abordadas. Mas a questão da oralidade ultrapassou o campo específico da antropologia, e agora é objeto de estudo de outras disciplinas, como é o caso, atualmente, da corrente historiográfica denominada "história oral". (p. 40)

Vô Werno Abraham, um adorável e exímio contador de histórias, no fim de sua vida, gostava de ficar sentado à janela, observando o movimento da rua e a agitação na vida das pessoas. Ao nos aproximarmos, principalmente em dias de chuva, quando minha avó Eddy, fazia waffelsback (waffers), gostava de contar fatos pitorescos de sua infância no campo. Não adotou as tecnologias do mundo moderno. Morreu aos 81 anos de idade sem ter em casa sequer um aparelho de televisão. Nossas visitas eram, sempre, repletas de boas e animadas histórias.

Bosi (1994), em seu livro Memória e Sociedade: lembranças de velhos, nos adverte sobre a riqueza presente na memória dos idosos.

Um verdadeiro teste para a hipótese psicossocial da memória encontra-se no estudo das lembranças das pessoas idosas. Nelas é possível verificar uma história social bem desenvolvida: elas já atravessaram um determinado tipo de sociedade, com características bem marcadas e conhecidas; elas já viveram quadros de referência familiar e cultura igualmente reconhecíveis: enfim, sua memória atual pode ser desenhada sobre um pano de fundo mais definido do que a memória de uma pessoa 
jovem, ou menos adulta, que, de algum modo, ainda está absorvida nas lutas e contradições de um presente que a solicita muito mais intensamente do que a uma pessoa de idade. (p.60)

Vô Werno, saudoso dos seus tempos de criança, lembrava que o espaço da escola era local de muita rigorosidade comportamental. Narrava, com certo ar de desentendimento a severidade e a intolerância que marcaram a época. Momento em que os povos pomeranos estavam se fixando nesta localidade. Uma das maiores dificuldades no acesso e permanência na escola era a transposição da língua materna (utilizada em casa) para a língua oficial do país, o Português. O professor fazia um trabalho inicial de tradução, porém eram muitas as informações, dificultando a aprendizagem, aumentando os casos de evasão escolar.

Küster (2018) retrata esta realidade ao destacar que no:

[...] primeiro contato com a escola, minha reação foi de estranhamento. Inúmeras preocupações fervilhavam na minha mente: como eu daria conta de aprender a falar uma nova língua e também de assimilar todo o conteúdo proposto? Não conseguia entender por quê, naquele espaço, nossa língua era totalmente anulada e corríamos até riscos de punição física e moral, se ousássemos usá-la. No primeiro momento, eu só pensava em fugir daquele lugar. Mas, como os colegas veteranos se propunham a ajudar os iniciantes, eu e os outros alunos da minha sala que também eram descendentes de pomerano enfrentamos isso de uma forma menos constrangedora. (p. 22)

Apesar dos castigos, que frequentemente recebiam na escola, aplicados pelo professor que também era o pastor a época, eram momentos de muita aprendizagem e confraternização. Contava que os alunos realizavam muitas façanhas, com frequência, como a dos meninos que copiavam as lições das meninas, espiavam debaixo de suas saias ao fingir que estavam caindo e das brincadeiras no caminho para chegar à escola.

Outro fato que achávamos muito interessante, era o de não haver cadernos. Os netos se divertiam ao ouvir as histórias do vô Werno que aconteceram lá no ano de 1969, passados mais de 70 anos. As narrativas eram tão reais que costumavam brincar, dentro do imaginário infantil, reproduzindo os alunos da época com pedaços de madeira e carvão.

Em sua fala era evidente a preocupação dos pais com a educação formal. Durante um bom tempo do ano precisariam produzir alimentos na lavoura e criar animais, que seriam vendidos, para que os filhos frequentassem à escola e pudessem adquirir os livros.

Por outro lado, a questão de gênero, desde cedo, eram construídas de forma pejorativa, no que tange a direitos, com as crianças. Na fala do Vô Werno havia um destaque ao fato de que tudo era mais fácil quando as meninas não tinham direito a frequentar a escola, pois as despesas da família eram menores. Porém, com o passar do tempo, as coisas foram mudando e as meninas começaram a ter o direito de frequentar à escola, precisando de uniforme e livros.

Ele contava que as famílias começaram a perceber que a escolarização também era importante para as meninas, pois precisavam ler e escrever para bordarem e escrever em pomerano. É neste momento que surgem as turmas mistas ainda nas igrejas locais. Ainda, das lembranças do vô Werno, ênfase, pela entonação de voz, ao falar da distância para se chegar até a escola. Eram quilômetros percorridos a pé, com raras exceções, a cavalo ou de carroça. Grupos de amigos se formavam ao longo do caminho, cruzavam pontes de madeira e pinguelas, tronco de árvore derrubado por cima do córrego 
para travessia, muitas vezes escorregadio, perigoso, mas era o único jeito de se chegar ao destino. Descalços e com uniformes que ficavam cada vez mais curtos com o passar dos anos. O vô contava que apesar das dificuldades, eles se divertiam em situações que aconteciam naquele tempo, fossem as brincadeiras entre ele e seus colegas, como as que realizavam com o professor, quando "esqueciam", (risos) de amarrar bem o seu cavalo.

Das muitas histórias contadas há uma que retrata bem como eram tratadas as peraltices de criança. Segundo Vô Werno certo dia seu pai liberou a carroça para que, ele e seus irmãos, fossem à escola. No caminho havia um arroio e os cavalos não quiseram atravessar, ele desceu para guiar os cavalos e acabou por molhar seu uniforme (tapapó) ao chegar à escola o professor o colocou de castigo de joelhos atrás da porta durante todo o período de estudos.

Com as inúmeras atividades da igreja como sepultamentos, missas, e preparação para o ensino confirmatório, a comunidade percebeu que as igrejas não eram o local mais apropriado para ser escola, pois frequentemente os alunos eram dispensados de suas aulas, sendo prejudicados.

Vô Werno faleceu no ano de 2014 e sua esposa Vó Eddy no ano de 2018, aos 88 anos de idade. Ela, da mesma forma, lembrava dos tempos de escola com certa nostalgia, destacando que a aprendizagem dos alunos era reflexo da rigidez e autoridade do professor que exigia dos alunos uma caligrafia perfeita, com traços circulares. As meninas, no início, não tinham direito à escola, pois a elas precisavam saber cozinhar, lavar, aprender as práticas de conservas de alimentos, produção de chimias, cucas, pães, biscoitos e embutidos, essenciais para a manutenção dos costumes e tradições daquela época.

Em suas lembranças relatava a austeridade do professor com relação ao uniforme, que deveria ser de um branco impecável. No tempo de inverno muito rigoroso, com chuvas e garoas que se perpetuavam por vários dias, um colega foi para aula sem a camisa do uniforme, foi agredido pelo professor com um tapa no rosto e permaneceu de joelhos atrás da porta durante todo o tempo da aula. Servia de lição! Para que ninguém se atrevesse a aparecer sem o uniforme.

Os imigrantes foram expectadores das mudanças na área da educação. Algumas memórias de professores, que lecionaram junto as primeiras escolas multisseriadas no município de Canguçu, serão resgatadas neste espaço.

Sobre estas lembranças, Alberti (2004), em uma palestra de abertura do VII Encontro Nacional de História Oral, versa sobre a importância dos guardiões de memórias, memórias de seus mitos, que foram ao longo do tempo sendo informados pelos seus antepassados, quer dizer os narradores de tradição oral. (p.17).

Vô Werno e Vó Eddy contavam que as suas filhas quando começaram a frequentar a escola não havia mais tanto rigor na escolha dos professores. Para ser docente bastava ser uma pessoa da comunidade que demonstrasse algum interesse pelo ensino. Geralmente meninas, recém concluintes da $4^{a}$ série do ensino fundamental ou até antes disso, que possuíam capricho e organização com os materiais escolares. Estas professoras leigas não possuíam vínculo empregatício. Além da docência eram 
responsáveis pela documentação referente a matrícula, ao boletim escolar, aos registros avaliativos, entre outros.

Conta se que com o passar do tempo, o município começou a se organizar e criou uma secretaria de Educação (SEDUC). A primeira ação daquele espaço era o de enviar alimentos para as escolas. 0 preparo, somando mais esta função, ficava a cargo das professoras. Uma das filhas do Vô Werno contou que muitas vezes as crianças ajudavam no cuidado e preparo da merenda.

A SEDUC, no que tange aos aspectos do ensino, iniciou disponibilizando material didático para os planejamentos dos professores leigos que lecionavam, naquela época, para quatro turmas de diferentes níveis de aprendizagem. A partir do planejamento foi percebida a necessidade de uma formação mais específica para os docentes em exercício do magistério. Foram, então, estes professores, convocados a uma reunião em que foi explanada a proposta de realização de um Curso Básico de Magistério, no período de férias, na cidade vizinha, Morro Redondo.

Em meados do ano de 1965, os professores leigos, alunos do Curso de Magistério se reuniam por um período de dois a três meses para a denominada Formação Pedagógica (FP) que os "capacitava" para o exercício da docência.

Nörnenbeg (2008), em sua tese de doutorado, aborda o cotidiano de uma professora daquela época. Relata que

[...]foi uma conversa informal, que ora relembrava nosso passado e ora situava o seu estar/ser professora, suavemente. Esse balanço trouxe em seu movimento informações extremamente interessantes, como, por exemplo, a maneira como ela foi escolhida para ser professora, o desafio de, com apenas a terceira série primária, lecionar para uma quarta série, os cursos que frequentou e, acrescido a isso, a preocupação e o compromisso de fazer o melhor possível. (p.73, grifo nosso.)

O que se percebe nesta citação é o quão frágil era a preocupação com a educação. As pessoas, para o exercício do magistério, eram escolhidas aleatoriamente, sem nenhuma preparação. Professores podiam ser menos escolarizados do que seus alunos. Um forte indicador de precarização do trabalho docente e da educação.

Nörnenbeg (2008) cita, ainda, em seus estudos, que os índices de reprovação eram elevados, muitos alunos que chegavam à escola falando somente o dialeto pomerano, língua materna, necessitavam de, pelo menos, um ano para aprender a se comunicar em português. Somente no ano seguinte começavam a se alfabetizar para em mais um repetir a mesma etapa e conseguir êxito.

Não se percebia, como destaca o autor, naquela época, preocupação com a aprendizagem ou não dos alunos. Segundo o autor era apenas uma troca: a SEDUC responsável pela educação do município e que dispunha de recursos financeiros e os professores que desenvolviam seu trabalho de forma mecanizada.

Em Santa Maria de Jetibá no Espírito Santo ocorreu situação semelhante com os descentes de pomeranos. Kuster (2018) descreve situações de descaso com a educação, principalmente com as crianças que chegavam as escolas falando somente a língua materna. Destaca que 
situação levou a Igreja Luterana a investir na construção de escolas paroquiais, geralmente, ao lado dos templos, em regime de mutirão. Essas escolas serviam tanto para as aulas como para os cultos. Com a ajuda de vários imigrantes recém-chegados, que foram também professores, os pomeranos passaram a ter acesso a instrução escolar, com aulas ministradas em alemão. (KUSTER, 2018, p.50)

Uma realidade que se repete em outros estados e que, de alguma forma, denuncia o descaso com que a educação é tratada. Freire (1987), ao abordar a Educação Popular, enfatiza que o processo pedagógico tem o ser humano como ser único, consciente de seu inacabamento. O acesso ao saber o conduz à aprendizagem levando o indivíduo a conhecer-se e conhecer o mundo que o cerca. Sendo assim, a educação, na ótica freireana, é um instrumento único e essencial nos processos de libertação do indivíduo e da sociedade.

Nörnenbeg (2008), por sua vez, descreve que a maioria das crianças chegavam à escola falando o dialeto materno e que demoravam um longo período para efetuarem a transição para a língua portuguesa. Fora da sala de aula era comum os alunos se reunirem, na hora do recreio e em atividades extraclasse, e se comunicarem em pomerano. Isto, de certa forma, dificultava o aprendizado do Português.

Este processo de conhecimento de outra língua era difícil e para agravar, ao final do ano letivo, as supervisoras da SEMED iam a escola aplicar provas, desconectadas da realidade dos alunos, e, involuntariamente, acabavam intimidando-os que, por nervosismo, não conseguiam obter êxito.

Muitas vezes o professor tentava ajudar como intérprete, porém, a inexperiência aliada ao desconhecimento do conteúdo, não ajudava muito. Este indicador também traduz a precariedade da formação destes profissionais para exercício da docência nos anos iniciais. Os professores haviam recebido a formação básica para lecionar nos anos iniciais, não dispunham de conhecimentos e, muito menos, recursos mais apropriados, afastando, desta forma, os alunos da escola. Não havia ambição de continuar estudando. Era necessário que a escola desenvolvesse outros atributos nestes estudantes que não apenas a ler (de forma precária e descontextualizada), escrever e calcular. Eram necessários agregar o seu conhecimento de mundo e de perspectivas futuras a cultura escolar. $E_{\text {, }}$ pelo que parece, não era interesse, visto que educação é poder e os imigrantes eram responsáveis pelo trabalho agrário, trabalhando em suas lavouras, plantado e colhendo não havendo assim necessidade de maior capacidade de entendimento principalmente relacionado as leis. Desta forma o que deveria ser ensinado nas escolas? Quais os conteúdos?

Quijano (2007, p. 22) adverte que:

[...] o sentido dos conteúdos [e] a finalidade da escolarização inicial é permitir que os alunos leiam, escrevam, façam quatro operações aritméticas, habilidades que são indispensáveis na nossa cultura. Entretanto, acreditamos também que as crianças precisam entender, em grau crescente de complexidade, o mundo onde elas estão. Precisam se entender, entender o outro, entender o mundo natural e social a partir da região onde vivem.

Haviam, ainda, para atender à necessidade dos estudantes, escolas multisseriadas que atendiam em um mesmo espaço, com a mesma professora, várias séries. Durante os anos seguintes a escola continuava assim, até que em meados do ano de 2005 dá-se início ao processo de fechamento destes espaços e o remanejamento dos alunos para as escolas maiores. Esta mudança gerou inúmeros 
transtornos, começando pelo transporte escolar para o deslocamento, a distância, acarretando em viagens longas e retorno para casa muito tarde.

Os alunos transferidos para as escolas polos acarretaram, também, o remanejamento docente. Porém, se nas escolas multisseriadas esses professores tinham dificuldade com conteúdos e um déficit de formação, a situação só tendia a ficar pior. Nas escolas não haviam tantas turmas das séries iniciais que comportassem a todos. Começaram, para compor a carga de trabalho, a trabalhar com componentes curriculares dos anos finais. Além da falta de formação, domínio do conteúdo, estava a dificuldade do aprofundamento de estudos em para que fossem trabalhados. O professor, mesmo leigo, precisava ler e estudar os assuntos para que pudesse dialogar com os alunos em sala de aula. Isso era cada vez mais difícil e a prática docente se resumia em copiar e ler pontos de livros didáticos.

Os professores vinham dos mais diversos lugares, realocados. O conhecimento da realidade do aluno se tornou cada vez mais insignificante. Os docentes desconheciam as necessidades do campo o que transformava a escola em um espaço estranho e a formação do estudante abstrata.

Por mais que houvesse esforço destes professores na tentativa de desenvolver, de forma satisfatória, o seu papel e trabalhar os conteúdos da matriz curricular era um empenho em vão. O professor de anos iniciais, na grande maioria leigo, lecionar em turmas dos anos finais com disciplinas específicas, como o caso do inglês, sem conhecimento da língua, era um desastre.

Muitas famílias não reconhecendo na escola um lugar legítimo para seus filhos, necessitando do trabalho inclusive infantil para o sustento, abrem mão da instrução. 0 acesso a estes espaços fica cada vez mais direcionado aqueles que possuem recursos financeiros e, desta forma, herdeiros das melhores vagas no setor empregatício.

\section{REFLEXÕES FINAIS}

Freire (1987) destaca a necessidade de uma educação que promova a cidadania em suas dimensões crítica, reflexiva e ativa. A educação popular, na ótica deste autor, deve subsidiar as massas oprimidas para que possam se libertar das mãos dos opressores. Uma educação que permita a libertação do "oprimido que hospeda o opressor". (Freire, 1987, p.17)

Ao longo do texto verificamos a presença do processo de escolarização para os imigrantes como um movimento, inicialmente, de forma unilateral, uma vontade popular, necessária.

Depois assumido, com aval da comunidade, pela igreja, fortemente vinculado ao credo religioso e, portanto, objeto de submissão. Posteriormente, ainda com uma forte vontade dos habitantes locais, pela SEMED. Toda riqueza de detalhes da história da educação do município de Canguçu e seus arredores, presente apenas na memória dos que viveram este tempo. Vislumbramos, neste artigo, um resgate, ainda que tímido, através da memória oral, desta história, e da forma como estes trabalhadores e suas famílias foram de forma gradual se desvencilhando da educação escolarizada. Como, de forma sutil, é passado de geração a geração que a educação mais tradicional, que imprime castigos, como atitude de formação é visto como positivo.

Pensamos em terminar este artigo dialogando sobre uma temática interessante tratada por Freire (1987) a liberdade. 
Ele interpreta a liberdade como um direito constitucional que permite a alvedrio de pensamento, de consciência. Como munir o oprimido deste atributo se ele o receia.

Raro, porém, é o que manifesta explicitamente este receio da liberdade. Sua tendência é, antes, camuflá-lo, num jogo manhoso, ainda que, às vezes, inconsciente. Jogo artificioso de palavras em que aparece ou pretende aparecer como o que defende a liberdade e não como o que a teme. (FREIRE, 1987, p. 24)

Em sua obra o autor busca coerência entre a razão humana e a consciência, pela qual o homem pode transformar-se e transformar o seu contexto social, e por isso a necessidade da formação do homem livre que vai a origem das coisas, não se deixando manipular, submete sua ação à reflexão.

Um ser humano que não se deixa massificar desenvolve uma consciência crítica, o ato de educar o conduz a liberdade, rebate a alienação por se compreender como um indivíduo que desenvolve suas potencialidades e se humaniza no exercício da responsabilidade que tem frente as mudanças sociais.

Diante da consciência crítica percebe as injustiças e a existência de opressores e oprimidos. Freire (1987) destaca que dentro de cada pessoa oprimida existe um opressor. A pedagogia da libertação é necessária para que o oprimido tome consciência da existência de um opressor dentro dele, e ao abandonar a condição de oprimido não se torne um opressor.

\section{REFERÊNCIAS}

BOSENBECKER, Patrícia. Uma colônia cercada de estâncias: imigrantes em São Lourenço/RS(1857-1877). Dissertação de mestrado. Programa de pós-graduação em História do Instituto de Filosofia e Ciências Humanas da Universidade Federal do Rio Grande do Sul, Porto Alegre, 2011

BOSI, Ecléa. Memória e Sociedade- Lembranças de velhos. $3^{\circ}$ ed. São Paulo. Companhia das letras, 1994.

BEILKE, Neubiana Silva Veloso. POMMERSCHE KORPORA: uma proposta metodológica para compilação de corpora dialetais. Dissertação mestrado. Programa de Pós-Graduação em Estudos Linguísticos do Instituto de Letras e Linguística da Universidade Federal de Uberlândia, 2016.

FERREIRA, Marieta de Moraes; AMADO, Janaína. [orgs.] Usos \& abusos da história

oral. Rio de Janeiro: FGV, 2006.

FREITAS, Sônia Maria de. História Oral: possibilidades e procedimentos. São Paulo: Associação Editorial Humanitas, 2006.

FREIRE, Paulo. Pedagogia do Oprimido. 17a ed. Rio de Janeiro: Paz e Terra, 1987.

FREIRE, Paulo; NOGUEIRA, Adriano. Que fazer: teoria e prática em educação popular. Petrópolis: Vozes, 1989.

HACKENHAAR, Daniele. Vida e trajetória do povo pomerano: a imigração pomerana para o brasil. Trabalho de Conclusão de Curso licenciatura em História. Universidade Federal de Santa Catarina, 2018.

KÜSTER, Sintia Bausen. A cultura e a língua pomeranas vão à escola. $1^{\circ} \mathrm{ed}$. Curitiba: Appris, 2018. 
M'BOW, M. Amadou Mahtar. Prefácio. In: História Geral da Africa - Metodologia e pré-história da África. Editado por Joseph Ki-Zerbo . 2.ed. rev. Brasília: UNESCO, 2010. p. 21-26.

QUIJANO, Graciela Reyna. Jornada de educação popular: pelo encontro da escola com a vida. Editora da UFRGS, Porto Alegre, 2007.

TIMM, Graciéli Abrahm Griep. Colonização Pomerana: Dificuldades de Aprendizagem. Canguçu, 2009.

VANSINA, Jan. A tradição oral e sua metodologia. In: História Geral da Africa - Metodologia e pré-história da África. Edit. por Joseph Ki-Zerbo . 2.ed. rev. Brasília: UNESCO, 2010. p. 139-166. 